\title{
A New Method of Synthesis Carbon with Onion-Like Structure with High (10-13\%) Content of Nitrogen from Pyridine
}

\author{
Alexey Kharlamov ${ }^{1}$, Marina Bondarenko ${ }^{1, *}$, Ganna Kharlamova ${ }^{2}$, Nadezhda Gubareni ${ }^{1}$, \\ Veniamin Fomenko ${ }^{1}$ \\ ${ }^{1}$ Frantsevich Institute for Problems of Materials Science of NASU, Krzhyzhanovsky St. 3, 03680 Kiev, Ukraine \\ ${ }^{2}$ Taras Shevchenko National University of Kiev, Volodymyrs'ka St. 64, 01601 Kiev, Ukraine \\ *Corresponding Author: dep73@ipms.kiev.ua
}

Copyright $(0) 2013$ Horizon Research Publishing All rights reserved.

\begin{abstract}
The new method of pyridine pyrolysis is created, the some part of pyrolytic soot of which contains onion-similar carbon with high $(10-13 \%)$ contents of nitrogen (or "pyridine carbon"). Nanoparticles of this "pyridine carbon" are formed only in a gas phase at the expense of reactions of polymerization and polycondensation of molecules of pyridine and by reactionary flow in a low-temperature zone of reactionary space are taken out. Onion-structures of the greater size and with the small contents of nitrogen $(\sim 1.0 \%)$ together with nanotubes and filaments are products of heterogeneous reactions between carbon fragments of destruction of pyridine molecules, which mainly on the most high-temperature surface of quartz reactor are carried out. Nitrogen-containing fragments of a destruction of a molecule $\mathrm{C}_{5} \mathrm{H}_{5} \mathrm{~N}$ mainly as $\mathrm{HCN}$ in a gas flow from sphere of reaction are removed. The growth of carbon nanostructures is realized at the expense of heterogeneous reactions but in absence of the metallic catalyst. The products were characterized by methods X-ray photoelectron and IR spectroscopy, scanning, transmission and high resolution transmission electron microscopy, X-ray diffraction and chemical analysis.
\end{abstract}

Keywords Onion-Like Carbon, Soot, Nitrogen, Pyridine, Pyrolysis

\section{Introduction}

At the end of XX century in the physics and chemistry the experimental results of epoch-making importance were created which have changed all our representations about composition and structure of our world, become the beginning in knowledge before of unknown world - the nanoworld. By means of electronic microscopy of the high resolution was found out and identified the new type of a matter (or new type of substance) as nanodimentional objects: nanoparticles, nanostructures and spheroidal molecules with hollow core (fullerenes and single-walled carbon nanotubes). It was established, that already well known substances can demonstrate new, unique properties depending on the size and morphology of nanoobject. Carbon molecules and nanostructures as well as non-carbon nanotubes and nanofilaments synthesized absolutely recently already today are widely used in nanoelectronics, medicine, catalysis as nanosensors $[1,2]$, sorbents $[3,4]$ and catalysts $[5,6]$. However, further application unique of carbon nanoforms (fullerenes, nanotubes, graphene and onions) can be even more scale in case of development of methods of controllable regulation their chemical and physical properties by means of, in particular, replacement in graphene layers of atoms of carbon by atoms nitrogen or boron with formation $\mathrm{N}-, \mathrm{Si}$ - or B-heterocarbon.

The atoms of nitrogen, boron or silicon introduced in a carbon matrix are capable to change an electron capacity of heterocarbon and to cause the disorder and essential distortion of graphene layers. Thus, electron-acceptor property obtained, for example, N-heterocarbon significantly change and depend on amount of the introduced atoms of nitrogen and the state of it valency. Some synthesized nanoforms of N-heterocarbon are already successfully applied as catalysts and supports of catalysts [5], sorbents to clearing gases [3] and liquids [4] from polluting substances. $\mathrm{N}$-heterocarbon in electrochemical processes for creation of super capacitor and fuel elements [7] also are used. Usually $\mathrm{N}$-heterocarbon promotes increase as catalytic activity, in particular, metals, and selectivity of processes of the hydrogenation. So, on a basis N-heterocarbon are synthesized cathode catalysts [8] alternative to expensive traditional platinum catalysts. The active sites on this heteroatomic carbon are the ions of cobalt associated on the surface with atoms of nitrogen. 
Catalytic activity of N-heterocarbon sheets (synthesized at carbonization of collagen) in reaction of oxygen reduction is much higher than activity of the industrial catalyst Vulcan XC-72, containing $20 \%$ of platinum [9]. N-graphene shows also high electrocatalytic activity in reaction of reduction of hydrogen peroxide [10]. Adhesion of N-heterocarbon nanofibers with a polymeric matrix essentially raises [11], it is promotes increase of durability and durability of a composite. It is considered [12] that C-N-nanotubes can become a basis at creation of element base of devices for solid-state electronics. The support on a basis $\mathrm{N}$-heterocarbon prepared by pyrolysis of a composite on the basis of polyanilines significantly raises productivity of the platinum catalyst of electrochemical oxidation of methanol [13]. C-N-nanotubes are used as the support of palladium as catalyst of liquid-phase hydrogenation of cinnamaldehyde $\left(\mathrm{C}_{6} \mathrm{H}_{5} \mathrm{CH}=\mathrm{CHCHO}\right)$ in perfumery and food-processing industry [14]. The N-containing carbon obtained by pyrolysis of polypyrrole $/ 2.2$ '-bipyridine composite is the effective catalyst of reaction of oxygen reduction [15]. $\mathrm{N}$-heterocarbon also in fuel elements with a proton exchange membrane is applied [16]. N-heterocarbon nanostructures as the catalysts reduce with $1.3 \mathrm{eV}$ up to $0.9 \mathrm{eV}$ [17] power barrier of dissociative adsorbtion of hydrogen and, consequently, are rather perspective for the hydrogen storage. However, it is supposed [16] that mainly atoms of nitrogen of pyridine type are catalytically the active sites of $\mathrm{N}$-containing carbon which contents can grow with increase of a degree of nitrogenation a carbon matrix. Nitrogen-containing sites on a surface of N-heterocarbon supports promote uniform distribution of the metallic catalyst and increase it thermostability [18]. Therefore question on development of effective methods of synthesis of different nanostructures of N-heterocarbon with the large contents of nitrogen is extremely urgent.

In present time $\mathrm{N}$-heterocabon obtain or at pyrolysis of vapours of nitrogen containing organics [19-21], or at the nitrogenation of previously the synthesized samples of carbon nanostructures in nitrogen containing atmosphere. So, $\mathrm{N}$-heterocarbon nanotubes and nanofilaments synthesize from acetonitrile $\left(\mathrm{CH}_{3} \mathrm{CN}\right)$, melamine $\left(\mathrm{C}_{3} \mathrm{H}_{6} \mathrm{~N}_{6}\right)$, iron phthalocyanine $\left(\mathrm{C}_{32} \mathrm{H}_{18} \mathrm{~N}_{8}\right)$, dimethylformamide $\left(\mathrm{C}_{3} \mathrm{H}_{7} \mathrm{NO}\right)$, pyridine or such mixes as acetylene / ammonia, $\mathrm{CH}_{4} / \mathrm{N}_{2}[19$, 20]. At pyrolysis of nitrogen containing hydrocarbons usually obtain N-heterocarbon with the large contents of nitrogen, than at heat treatment of mixes with a presence of ammonia or nitrogen. Carbon nanotubes prepared at pyrolysis of acetonitrile at $900^{\circ} \mathrm{C}$ and pressure 5 bars contain up to 3 mass $\%$ of nitrogen [21]. From melamine ( 66.7 mass $\%$ of nitrogen) and pyridine (17.1 mass $\%$ of nitrogen) are formed multiwall $\mathrm{N}$-carbon nanotubes with the contents only 5 and $2 \%$ of nitrogen accordingly [22]. At nitrogenation of previously synthesized nanostructures of carbon obtain $\mathrm{N}$-heterocarbon with the low contents of nitrogen while at use of the catalyst promoting its increase N-heterocarbon becomes soiled by the particles of the catalyst.

In the given paper the experimental results on the study of
$\mathrm{N}$-containing onion-like carbon with large ( 13 mass\%) contents of nitrogen as the product obtained at the realization of a new method of pyrolysis (NMP) of pyridine vapours are submitted. N-doped carbon spherical particles by a diameter from $40 \mathrm{~nm}$ up to $1000 \mathrm{~nm}$ obtained earlier [23] at a usual method of pyridine pyrolysis (or the mixes of pyridine with toluene) at $1000^{\circ} \mathrm{C}$ only up to 5 mass $\%$ of nitrogen are contained. The idea of creation of the new approach for obtaining of $\mathrm{N}$-doped carbon with the much larger contents of nitrogen consists in the following. Pyridine molecule in contrast to benzene molecule is more inclined to the destruction with the subsequent formation not only closed carbon molecules, but also various mono- and heteroatomic structures, in particular nitrogen containing soot. In process of pyrolysis on the most high-temperature part of the surface of quartz reactor are realized mainly endothermic heterogeneous reactions of the destruction of molecules of precursor, at which the nitrogen as $\mathrm{HCN}$ [24] from sphere of reactions is removed. Therefore the product in this zone of reactor with the minimal contents of nitrogen only is formed, that, in principle, in $[22,23]$ was shown. The radical reactions, in particular, polymerization and polycondensation of an activated molecule of pyridine mainly in volume of reactor can proceed as a result of which, in particular, heteroatomic fullerene-like molecules are formed [25]. One of products these extremely exothermal reactions, undoubtedly, $\mathrm{N}$-doped carbon can be. To obtain N-heterocarbon with much more contents of nitrogen we can just in that case if a time of stay of reagents (and, hence, the duration of gas-phase exothermal reactions) in reactionary space a little to increase, in particular, at the expense of localization of products of radical reactions far from a high-temperature zone as places of a beginning of transformations of precursor.

\section{Materials and Methods}

The study high-temperature $\left(900-1000^{\circ} \mathrm{C}\right)$ of transformation of pyridine vapours is carried out on a typical (for method of continuous flowing pyrolysis (CFP) of vapours of pyridine $[22,23]$ installation with use of tubular quarts reactor. However, reactionary conditions NMP of pyridine are not typical both for usual CFP and pulse (IP) methods of pyrolysis, in particular, concerning input of reagents (amount and speed) and a place of localization of condensed and deposited substances. The feature of NMP consists in creation of such conditions of heat treatment of pyridine, at which the products activated and formed in the most high-temperature zone A $\left(900-1000^{\circ} \mathrm{C}\right)$, partially are deposited and mainly are condensed in low-temperature zones $\mathrm{B}\left(<400^{\circ} \mathrm{C}\right)$ and $\mathrm{C}\left(<70^{\circ} \mathrm{C}\right)$ reactionary space. A product as soot here is characterized which at pyrolysis pyridine in absence of the in volumetric reactionary space catalyst is formed only, but in zones B and C is deposited. For obtaining of soot with the greatest contents of nitrogen the experiments are carried out at a variation of various technological (choice of zones B and C of localization of 
soot) and reactionary (temperature, concentration of precursor and time of its stay in the most high-temperature zone A) of parameters. At each of two optimized regimes (1 and 2) several (8-10) experiments are carried out. Maximal temperature for a regime 1 is $1000^{\circ} \mathrm{C}$ and for regime 2 is $940^{\circ} \mathrm{C}$. The duration of each experiment at heat treatment of pyridine does not exceed 2.5 hours. After cooling reactor up to room temperature the products from each of three zones (A, B and C) were taken. Then products, for example, the zone B, obtained at 8-10 experiments carefully mixed as the processes of pyrolysis, as is known, are characterized by not enough reproducibility on composition and amount of obtained products. From the average samples synthesized at a regime $1(\mathrm{~A} 1, \mathrm{~B} 1, \mathrm{C} 1)$ (or at a regime $2(\mathrm{~A} 2, \mathrm{~B} 2, \mathrm{C} 2))$ the substances, soluble in ethanol and toluene were extracted.

Samples of the soot after an extraction of soluble substances are characterized by methods X-ray photoelectron (XPS) and IR spectroscopy, scanning (Superprobe-733), transmission (JEOL JEM-100CX) and high resolution transmission (Philips CM200) electron microscopy as well as by the X-ray diffraction (XRD) and chemical analysis. X-ray diffraction study of powders was fulfilled on DRON-UM diffractometer with $\mathrm{Cu} \mathrm{K}{ }_{\alpha}$-radiation and nickel filter.

XPS valence-band and core-level spectra of the product synthesized by using the UHV-Analysis-System assembled by SPECS Surface Nano Analysis Company (Germany) were measured. The system is equipped with a PHOIBOS 150 hemispherical analyzer. A base pressure of a sublimation ion-pumped chamber of the system was less than $5 \times 10^{-10}$ mbar during the present experiments. The $\mathrm{Mg}$ $\mathrm{K} \alpha$ radiation $(E=1253.6 \mathrm{eV})$ was used as a source of XPS spectra excitation. The XPS spectra were measured at the constant pass energy of $25 \mathrm{eV}$. The energy scale of the spectrometer was calibrated by setting the measured $\mathrm{Au} 4 \mathrm{f}_{7 / 2}$ and $\mathrm{Cu} 2 \mathrm{p}_{3 / 2}$ binding energies to $84.00 \pm 0.05 \mathrm{eV}$ and $932.66 \pm 0.05 \mathrm{eV}$, respectively, with regard to $E_{\mathrm{F}}$. For investigated sample, all the spectral features are attributed to the constituent element core-levels or Auger lines.

The FTIR spectra in a reflectance mode were recorded in the range from 4000 to $400 \mathrm{~cm}^{-1}$ with a spectral resolution of $8 \mathrm{~cm}^{-1}$ using a Nexus Nicolet FTIR spectrometer (Thermo Scientific) equipped with a Smart Collector reflectance accessory. Samples under investigation were powdered with $\mathrm{KBr}$ in 1:10 ratio.

\section{Results and Discussion}

According to X-ray diffraction (XRD) study the samples of soot deposited in different zones of reactionary space a little differ by a degree of ordering in graphene layers. The data of transmission electron microscopy (TEM) testify (Fig. 1A, Fig. 1B), that in a regime non-catalytic pyrolysis of pyridine solid oligomers of carbon in zones $\mathrm{B}$ and $\mathrm{C}$ are formed practically completely as spherical particles. The size of these particles of carbon significantly decreases at removal of a place of them deposition from a high-temperature zone A, that is, certainly, quite natural. These particles represent as follows from high resolution transmission electron microscopy (HR TEM) images (Fig. 1C) fairly orderly onion-similar structure of carbon. As against zones $\mathrm{B}$ and $\mathrm{C}$, where rather homogeneous on the size onions are formed, in a zone A the cobweb-like product consisting from spherical (Fig. 2A) and thread-like (Fig. 2B) nanostructures is formed.

Thus, it is important to note, that these huge carbon structures are formed in absence of any catalytic particles, which role in growth anisotropic nanostructures, probably, is too exaggerated. It is difficult to present that of such huge size $(>20 \mu \mathrm{m})$ fullerene-like carbon structure (Fig. 2A) is formed with participation metal nanoparticle as centre of its growth. (The detail mechanism of non-catalytic formation of carbon nanotubes and nanostructures by us is described earlier in [26]). Earlier also was shown [27], that in a zone A at benzene pyrolysis as spherical nanostructures (onions and toroids) and carbon nanotubes are formed.

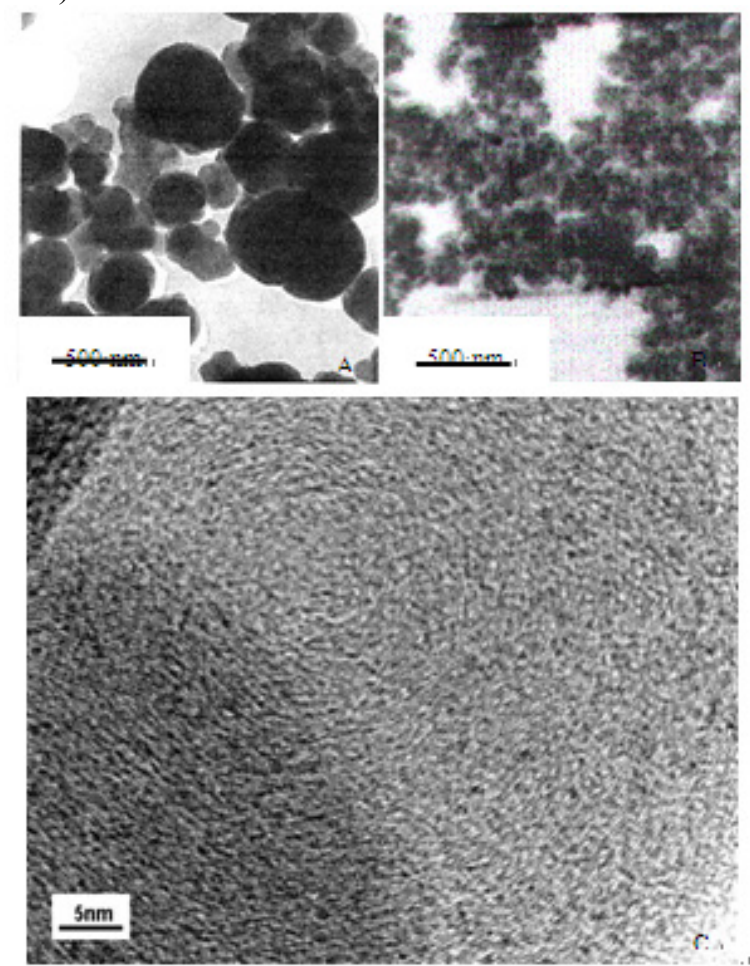

Figure 1. TEM images of products of zone B (Part A) and C (Part B) and HR TEM of image of product of zone C (Part C)

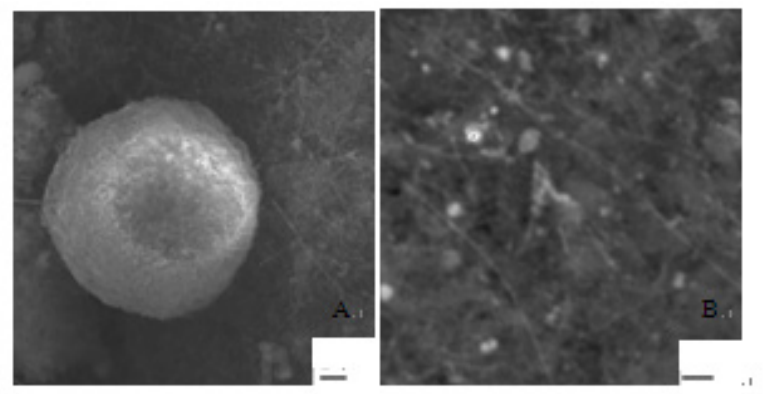

Figure 2. SEM images of products of zone A (Part A and Part B) 
According to the chemical analysis all samples of soot deposited in all three zones A, B and C, except for carbon contain also nitrogen, oxygen and hydrogen (Table 1). An amount, in particular, of nitrogen essentially depends on a regime of pyrolysis in a zone $\mathrm{A}$ and place of their localization in reactionary space. So, the amount of nitrogen in deposited soot significantly grows as at removal of a place of its localization from a high-temperature zone A, and with an increase of temperature of pyrolysis. It is remarkable, that the soot deposited in the zone A, practically always (in the investigated reactionary conditions) contains no more than $1 \%$ of nitrogen. The contents of nitrogen in a product of a zone $\mathrm{C}$ can reach more 10 mass\%. (Soot hypothetically consisting only from pyridine hexagons $\mathrm{C}_{5} \mathrm{NH}_{5}$ ("pyridine carbon") will be contain 17.2 mass\% of nitrogen.) The research of some samples of soot by means of XPS analysis has shown (Table 1), that surface layer (thickness up to $10 \mathrm{~nm}$ ) sample $C 1$ contains even greater (13.6 mass \%) amount of nitrogen.

XPS spectrum of a sample $\mathrm{C} 1$ with the highest contents of nitrogen is submitted on Figure 3A. From structure of spectra C1s (Fig. 3B) and N1s (Fig. 4A) it is possible to see, that a valency states of atoms of carbon and nitrogen are quite logical for already of investigated samples of $\mathrm{N}$-heterocarbon. The binding energy of $\mathrm{C} 1 \mathrm{~s}$ for a sample $\mathrm{C} 1$ is $284.9 \mathrm{eV}$ and is close on the value $(284.7 \mathrm{eV})[28,29]$ to binding energy of $\mathrm{C} 1 \mathrm{~s}$ for graphite-like $\mathrm{N}$-heterocarbon. So, in [28] is shown, that the C1s binding energy at increase of the contents of nitrogen in $\mathrm{N}$ - containing nanofilaments up to $8.2 \%$ grows only on $0.3 \mathrm{eV}$. As it is possible to see (Fig. 3B) $\mathrm{C} 1 \mathrm{~s}$ line in a sample $\mathrm{C} 1$ is significantly broadened and asymmetric that can testify to presence at a sample also of atoms of carbon with the value of binding energy more than
$286 \mathrm{eV}$. In [30], it is marked, that so high (286.9 and 288.6 $\mathrm{eV}$ ) the values of $\mathrm{C} 1 \mathrm{~s}$ binding energy are characteristic for $\mathrm{C}$ $=\mathrm{N}$ and $\mathrm{C}=\mathrm{O}$ bonds in particles of $\mathrm{N}$-heterocarbon. The value of binding energy at $\sim 288.1 \mathrm{eV}$ corresponds to carbon in $\mathrm{C}=\mathrm{N}$ and $\mathrm{C}-\mathrm{O}$ bonds in graphite-like nanoporosity [29] and amorphous [31] carbon nitride accordingly.

Significant broadening of a spectrum N1s of a sample C1 can be by a consequence of a superposition of two basic peaks correspond to pyridinic and quaternary atoms of nitrogen. In a spectrum N1s of a sample C1 (Fig. 4A) with the greatest contents of nitrogen (13.6 mass $\%$ ) pyridinic and quaternary atoms of nitrogen, probably, correspond to signals with binding energy at 399.8 and $400.4 \mathrm{eV}$ accordingly. In $[20,22,30,31]$ is shown, that the peak at $400.4 \mathrm{eV}$ in graphite-like $\mathrm{C}_{3} \mathrm{~N}_{4}$ corresponds to quaternary atom of nitrogen and the value $399.5 \mathrm{eV}$ assigns to pyridinic nitrogen in N-heterocarbon. Here it is necessary to note, that according to [22] the atom of nitrogen in N-graphene layer can be in 4 states: pyrrolic $\left(\mathrm{sp}^{3}\right)$, pyridinic $\left(\mathrm{sp}^{2}\right)$, quaternary (with not coupled electron) and nitrile-like or cyanogens-like $(-\mathrm{C} \equiv \mathrm{N})$. Thus, the atom of nitrogen having on one electron more, than next atoms of carbon, is capable to increase electronic capacity of N-heterocarbon.

In a spectrum O1s of a sample C1 (Fig. 4B) there are two distinct signals with binding energy at 532.0 and $532.9 \mathrm{eV}$, which according to the data [30] can assign $\mathrm{C}-\mathrm{O}$ and $\mathrm{C}=\mathrm{O}$ bonds in a heterocarbon.

IR spectrum (Fig. 5) of a sample $\mathrm{C} 1$ containing a maximum amount of nitrogen is most structured. The band at $815 \mathrm{~cm}^{-1}$ can corresponds to bonds $\mathrm{C}-\mathrm{H}$ in the conjugated systems and condensed CN-heterocycles [29, 31].

Table 1. Chemical composition of carbon soot samples obtained in the temperature zones A, B and C with different regimes of synthesis

\begin{tabular}{|c|c|c|c|c|c|}
\hline \multirow{2}{*}{ Temperature Zone } & \multirow{2}{*}{$\begin{array}{l}\text { Regime of } \\
\text { Synthesis }\end{array}$} & \multicolumn{4}{|c|}{ Elemental Analysis } \\
\hline & & Mass\% $\%$ & Mass $\%$ O & Mass \% C & Mass $\% \mathrm{H}$ \\
\hline \multirow{2}{*}{ A } & 1 & 0,9 & 1,0 & & - \\
\hline & 2 & 0,8 & 1,0 & & - \\
\hline \multirow[t]{2}{*}{ B } & 1 & $\begin{array}{c}4,1 \\
2,1 \text { (XPS) }\end{array}$ & $\begin{array}{c}1,1 \\
1,8 \text { (XPS) }\end{array}$ & $\begin{array}{c}94,1 \\
94,6 \text { (XPS) }\end{array}$ & 0,23 \\
\hline & 2 & 2,9 & 4,0 & & $<0,001$ \\
\hline \multirow[t]{2}{*}{$\mathrm{C}$} & 1 & $\begin{array}{c}10,5 \\
13,6 \text { (XPS) }\end{array}$ & $\begin{array}{c}\text { 6,6 } \\
\text { C } 3,9 \text { (XPS) }\end{array}$ & $\begin{array}{c}82,1 \\
82,5 \text { (XPS) }\end{array}$ & 0,8 \\
\hline & 2 & 8,1 & 1,1 & 90,1 & 0,23 \\
\hline
\end{tabular}



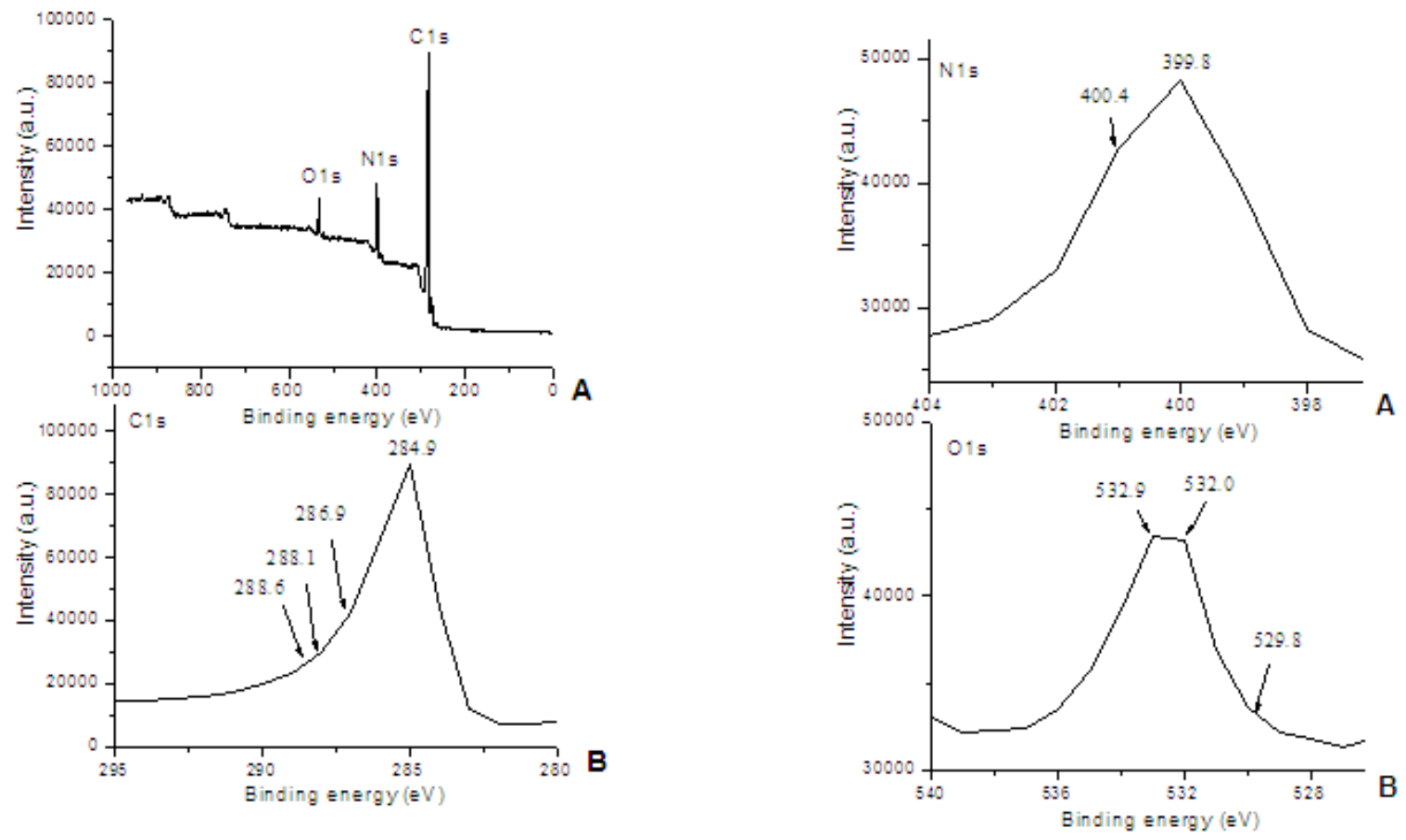

Figure 3. XPS survey (Part A) and core level C 1s (Part B) spectra of product C1

Figure 4. XPS core level $\mathrm{N} 1 \mathrm{~s}$ (Part A), O 1s (Part B) spectra of product $\mathrm{C} 1$

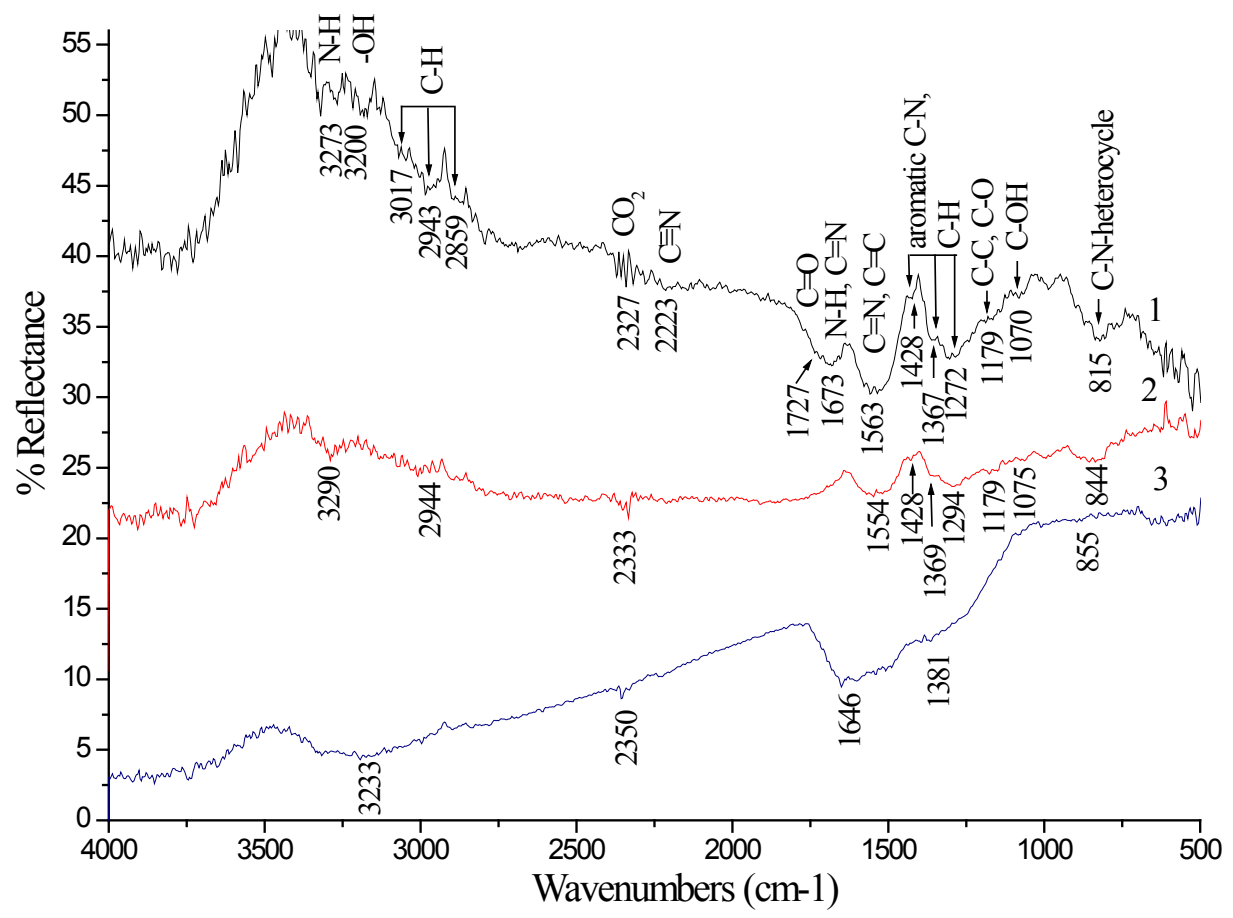

Figure 5. IR spectra of spectra of products $\mathrm{C} 1, \mathrm{~B} 1$ and $\mathrm{A} 1$ (curves 1, 2 and 3 respectively)

The bands at 1272, 1367 and $1428 \mathrm{~cm}^{-1}$ can correspond to stretching vibrations of aromatic bonds $\mathrm{CN}$ in condensed CN-heterocycles. So, the bands at 1255,1323 and $1428 \mathrm{~cm}^{-1}$ correspond to stretching vibrations of aromatic $\mathrm{CN}$-bonds in graphite-like nanoporosity carbon nitride of stoichiometric composition $\mathrm{C}_{3} \mathrm{~N}_{4}$ [29]. Is remarkable, that IR spectra of samples of nanocarbon $\mathrm{C} 1$ and B1 (Fig. 5) contain also known band at $1428 \mathrm{~cm}^{-1}$. Just this absorption band is characteristic for fullerene $\mathrm{C}_{60}$ and can correspond to vibrations of a carbon skeleton with the conjugated bonds. 
The band at $1563 \mathrm{~cm}^{-1}$ is assigned, probably, to bonds $\mathrm{C}=\mathrm{N}$ : the appreciable tendency of increase of intensity of this line is visible in process of increase of the contents of nitrogen in a sample. Though it is necessary to note, that in dicyanogen $(\mathrm{CN}) \mathrm{x}$ and in many other substances containing bonds $\mathrm{C}=\mathrm{N}$, the absorption band is exhibited at $1570 \mathrm{~cm}^{-1}$, i.e. as well as a band of bonds $\mathrm{C}=\mathrm{C}$. Besides two bands of absorption at 1571 and $1630 \mathrm{~cm}^{-1}$ [29] close to the values for a sample $\mathrm{C} 1$ are exhibited distinctly in graphite-like nanoporosity carbon nitride of stoichiometric composition $\mathrm{C}_{3} \mathrm{~N}_{4}$ [29] and correspond to bonds $\mathrm{C}=\mathrm{N}$. The bands of absorption at $1715-1730 \mathrm{~cm}^{-1}$ are usually characteristic for $(-\mathrm{C}=\mathrm{O})$ groups. The weak signal at $1727 \mathrm{~cm}^{-1}$ in IR spectrum of a sample $\mathrm{C} 1$ can be assigned to group $(-\mathrm{C}=\mathrm{O})$. Observable some displacement of the bands of absorption for bonds $\mathrm{C}=\mathrm{N}$ and $\mathrm{C}=\mathrm{O}$, probably, is caused by the defects in the connected structure of $\mathrm{N}$-containing carbon matrix. The very weak bands in a sample $\mathrm{C} 1$ at 2223 and $2327 \mathrm{~cm}^{-1}$ can correspond to the insignificantly presence of bond $\mathrm{C} \equiv \mathrm{N}$ and adsorbed $\mathrm{CO}_{2}$ on surface of powder respectively. However, we note that in a IR spectrum fluorescent $\mathrm{N}$-containing carbon nanoparticles prepared by a boilling of carbon soot in $5 \mathrm{M}$ nitric acid, nitrile group $\mathrm{C} \equiv \mathrm{N}$ is exhibited at 2335 and 2360 $\mathrm{cm}^{-1}$ [30]. The weak bands at 3200 and $3273 \mathrm{~cm}^{-1}$ can assign to stretching vibrations in bonds $-\mathrm{NH} 2$ (or $=\mathrm{NH}$ ) of amine groups $[29,31]$ as well as groups $-\mathrm{OH}$ which, probably, at insignificant amounts in a sample are available. The weak bands at 1179 and $1070 \mathrm{~cm}^{-1}$ testify to presence at a sample $\mathrm{C} 1$ of the bonds $\mathrm{C}-\mathrm{O}$ and $\mathrm{C}-\mathrm{OH}$ accordingly. The bands at 2859, 2943 and $3017 \mathrm{~cm}^{-1}$ (very weak in a sample) usually correspond to bonds $\mathrm{C}-\mathrm{H}$.

In contrast to a sample $\mathrm{C} 1$ of the absorption bands in a sample $\mathrm{B} 1$ (Fig. 5) corresponded to bonds $\mathrm{C}=\mathrm{N}$ are expressed to a lesser degree and in short-wave area of a spectrum a little are displaced. So, the bonds $\mathrm{C}=\mathrm{N}$ are exhibited by broadening of a band at $1554 \mathrm{~cm}^{-1}$. The broadening of this band can be also caused by a superposition of two bands responsible for the bonds $\mathrm{C}=\mathrm{N}$ and $\mathrm{C}=\mathrm{C}$. The bands at $1428,1369,1294 \mathrm{~cm}^{-1}$ in a sample $\mathrm{BP} 2$ can correspond to stretching vibrations of aromatic $\mathrm{CN}$ bonds usually observable in condensed $\mathrm{CN}$-heterocycles. Thus, the intensity of these bands in IR spectrum of sample B1 in comparison to sample $\mathrm{C} 1$ essentially it is less. The band at $844 \mathrm{~cm}^{-1}$ in a sample B1 can be assigned to bonds $\mathrm{C}-\mathrm{H}$ in the conjugated systems or (according to given [29]) in condensed $\mathrm{CN}$-heterocycles. The very weak bands at 1179 and $1075 \mathrm{~cm}^{-1}$ which in a sample $\mathrm{C} 1$ also are observed specify presence at a sample $\mathrm{B} 1$ of bonds $\mathrm{C}-\mathrm{O}$ and $\mathrm{C}-\mathrm{OH}$. Broad band at $3290 \mathrm{~cm}^{-1}$ assigns to stretching vibrations $\mathrm{N}-\mathrm{H}$ and $-\mathrm{OH}$ of groups and weak band at $2944 \mathrm{~cm}^{-1}$ for vibrations of $\mathrm{C}-\mathrm{H}$ group is characteristic. The weak band at $2333 \mathrm{~cm}^{-1}$ in a sample $\mathrm{B} 1$ can assign to adsorbed $\mathrm{CO}_{2}$ (or nitrile-like group in accordance with [30]).

Distinctive feature of a sample A1 (Fig. 5) obtained in a high-temperature zone $\mathrm{A}$ is, that in its IR spectrum practically there are no distinct bands. So, broadening peak at $1300-1450 \mathrm{~cm}^{-1}$, probably, is a superposition of three absorption bands at $1428,1371,1269 \mathrm{~cm}^{-1}$ which distinctly are visible in IR spectrum of a sample C1. These bands in [29] refer to condensed $\mathrm{CN}$-heterocycles. The very weak band at $854 \mathrm{~cm}^{-1}$ can also testify to presence of nitrogen in a sample A1. The wide bands at $1550-1650 \mathrm{~cm}^{-1}$ and at $3200-3300$ $\mathrm{cm}^{-1}$ can assign to stretching vibrations for bonds $\mathrm{C}=\mathrm{C}$ (or $\mathrm{C}=\mathrm{N}$ ) and $\mathrm{N}-\mathrm{H}$ (in group $-\mathrm{NH} 2$ or $\mathrm{NH}-$ ) accordingly.

According to the data IR and X-ray photoelectron spectroscopy the structure of a graphene layer of onion-like carbon formed at pyridine pyrolysis and containing more 10,0 mass $\%$ of nitrogen it is possible to present as "pyridinic graphene" layers (Fig. 6A) contained not benzene but pyridinic hexagons.

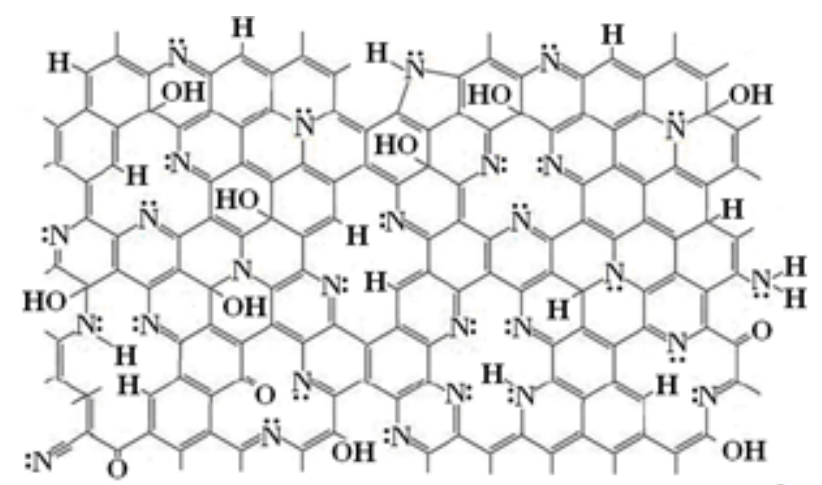

A.

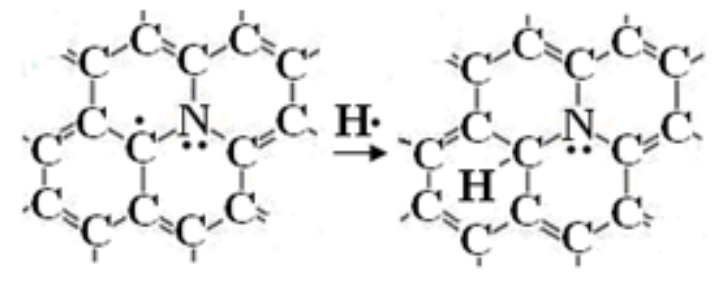
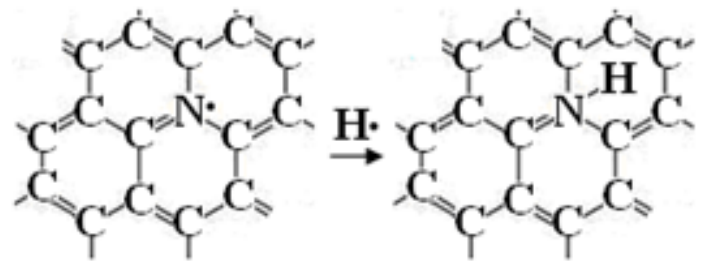

Figure 6. Scheme of a graphene layer of nitrogen containing onion-like carbon (Part A), fragments with 4-valent (Part B) and 3-valent (Part C) nitrogen atoms)

As it is possible to see, all types of the bonds $\mathrm{C}-\mathrm{N}$ which are found out in $\mathrm{N}$-containing carbon with the small contents of nitrogen [20, 22, 23, 28-31] are detected by methods IR and XPS also in "pyridinic carbon". The atom of nitrogen can form 3-rd multiple (replacement and pyrrole-similar), 2-nd multiple (pyridine-similar) and 1-st multiple (nitrile- or cyanogen-similar) bonds. The formation of pyrrole- and pyridine-like atoms of nitrogen in middle of pyridinic sheet can decrease the conjugation of system, but increase it electron capability. So, the pyrrole-like atom of nitrogen of $\mathrm{sp}^{3}$-hybridization replacing of atom of carbon in a graphene sheet, undoubtedly, decreases coplanarity of the $\mathrm{sp}^{2}$-conjugated system, but increases on one electron it 
electron capability. Therefore electron conductivity of $\mathrm{N}$-containing carbon with an increase of amount of atoms of nitrogen replacing atoms of carbon can a little grow. In [19, $20]$ it is supposed that the atom of nitrogen replacing atom of carbon can be 4-th valence: to have one double bond with one of the 3-rd nearest atoms of carbon and one free electron (Fig. 6C). The atom of nitrogen in such state practically cannot change the conjugation and planarity of system. However an electron capability of "pyridinic graphene" with 4-th valence atom of nitrogen is increased by one electron. Let's note, that 4-th valence nitrogen atom exists, as a rule, in donor-acceptor complexes, therefore existence 4-th valence of nitrogen with super-octet electron (as a radical) in "pyridinic carbon" is improbable.

Thus, the submitted experimental results convincingly show that pyrolysis of pyridine vapours in the especially created reactionary conditions can be finished by formation not only heteroatomic fullerene-like molecules [25, 32, 33] but also onion-like carbon containing rather large (10-13mass \%) amount of nitrogen. (Earlier [23], as was already marked, the onion-like carbon at pyridine pyrolysis was obtained only with the contents of nitrogen less than 5 mass\%). Here it is necessary to note that carbon onions found out for 10 years before opening of carbon nanotubes, remain, at the same time, least investigated from nanostructures of carbon because of extremely small effective methods of their obtaining [6, 23, 34-36]. The method of pyridine pyrolysis developed by us allows to synthesis "pyridinic carbon" in gram amounts.

There is a natural question: why to develop effective methods of obtaining, in particular, carbon onions with large amount of nitrogen despite of huge interest of the researchers to synthesis of heteroatomic carbon nanostructures it was not possible earlier. We believe, that the reactionary conditions created for realization standard, so-called «carbide», mechanism of formation of carbon nanotubes and filaments, are contrast productived (or not suitable) for synthesis of carbon molecules and spherical nanostructures. (Many experimental results inappropriate to the "carbide" mechanism of growth carbon nanostructures we already described and discussed [26, 27]). "Carbide" mechanism assumes indispensable decomposition of molecules of hydrocarbons up to atoms of carbon, i.e. the destruction strongest in hydrocarbons of bonds $-\mathrm{C}-\mathrm{C}-$ and $-\mathrm{C}=\mathrm{C}-$ as well as bonds $\mathrm{C}-\mathrm{H}$. The process of destruction of these bonds is extremely highly endothermic and can be realized only on a surface of metal capable to formation of carbide of this metal that in the most high-temperature zone A reactor is occurred usually. The destruction of bonds $\mathrm{C}-\mathrm{C}$ can proceed only because the formation of bonds $\mathrm{Me}-\mathrm{C}$ (metal-carbon) in carbide of this metall is more thermodinamic favourable. Therefore the "carbide" mechanism of forming of anisotropic nanostructures is more mechanistic, than chemical. It is known, that carbon nanotubes and especially nanofilaments grow also in absence of the catalyst and for joint formation of a molecule of fullerene and huge fullerene-like nanostructures (onions, toroids) this catalyst, in principle, is not required. These molecules and structures jointly are formed in a gas phase in result of highly exothermic reactions of polymerization and polycondensation not only activated molecules of precursor, but also fragments it destruction, from a high-temperature zone A by a reactionary flow are taken out and only in low-temperature zones of reactionary space are located (are deposited and are condensed). That is why numerous attempts to obtain appreciable amounts of nano-onions in the most high-temperature zone of reactor, in a zone of localization carbon nanotubes and nanofilaments are still small successful ones.

\section{Conclusion}

In contrast to known methods of pyrolysis we develop new reactionary conditions at which the realization onion-like carbon with large (10-13\%) contents of nitrogen (or "pyridinic carbon") is formed. "Pyridinic carbon" is formed in a reactionary flow at the expense of reactions of polymerization and polycondensation of molecules of pyridine and far from the most high-temperature zone of reactor is deposited.

\section{REFERENCES}

[1] N. Krainara, F. Illas, J. Limtraku. Interaction of adenine $\mathrm{Cu}$ (II) complexes with $\mathrm{BN}$-doped fullerene differentiates electronically equivalent tautomers, Chemical Physics Letters, Vol.537, No.1, 88-93, 2012.

[2] R. Lv, Q. Li, A. R. Botello-Méndez, T. Hayashi, B. Wang, A. Berkdemir, Q. Hao, A. L. Elías, R. Cruz-Silva, H. R. Gutiérrez, Y. A. Kim, H. Muramatsu, J. Zhu, M. Endo, H. Terrones, J. C. Charlier, M. Pan, M. Terrones. Nitrogen-doped graphene: beyond single substitution and enhanced molecular sensing, Scientific Reports, Vol.2, 586-590, 2012.

[3] M. G. Plaza, C. Pevida, A. Arenillas, F. Rubiera, J. J. Pis. $\mathrm{CO} 2$ capture by adsorption with nitrogen enriched carbons, Fuel, Vol.86, No.14, 2204-2212, 2007.

[4] G. G. Stavropoulosa, P. Samarasb, G. P. Sakellaropoulosa. Effect of activated carbons modification on porosity, surface structure and phenol adsorption, Journal of Hazardous Materials, Vol.151, No.2-3, 414-421, 2008.

[5] G. Nafise. CVD synthesis of nitrogen doped carbon nanotubes using iron pentacarbonyl as catalyst, Ph.D. Thesis, University of the Witwatersrand, Johannesburg, 2011.

[6] G. Wu, M. Nelsona, S. Mab, H. Mengc, G. Cuic, P. K. Shenc. Synthesis of nitrogen-doped onion-like carbon and its use in carbon-based $\mathrm{CoFe}$ binary non-precious-metal catalysts for oxygen-reduction, Carbon,Vol.49, No.12, 3972-3982, 2011.

[7] D. Hulicova, M. Kodama, H. Hatori. Electrochemical performance of nitrogen-enriched carbons in aqueous and non-aqueous supercapacitors, Chemistry Materials, Vol.18, 
No.9, 2318-2326, 2006.

[8] M. A. Kerzhentsev, O. U. Podyaeva, CH. N. Barnakov, A. V. Samaria. Ismagilov Synthesis and study of carbon nanomaterials for fuel cells. International Symposium Kuzbass Coal Chemistry and Ecology. Kemerovo. 2011. (Russian)

[9] Y. H. Lee, Y. F. Lee, K. H. Chang, C. C. Hu. Synthesis of $\mathrm{N}$-doped carbon nanosheets from collagen for electrochemical energy storage/conversion systems, Electrochemistry, Communications, Vol.13, No.1, 50-53, 2011.

[10] Y. Wang, Y. Shao, D. W. Matson, J. Li, Y. Lin. Nitrogen-Doped Graphene, Application in Electrochemical Biosensing, ACS Nano, Vol.4, No.4, 1790-1798, 2010.

[11] A. E. Shalagina. Catalytic synthesis and study of nitrogen-containing carbon nanofibers, Ph.D. Thesis, Novosibirsk, 2008. (Russian)

[12] O. E. Glukhova, O. A. Terentev. Theoretical study of the electronic and mechanical properties of single-walled nanotubes $\mathrm{CN}$, Physics of wave processes and radio systems, Vol.10, No.4, 4-7, 2007. (Russian)

[13] C. Zhou, Z. Liu, X. Du, D. Richard, G. Mitchell, Y. W. Mai, Y. Yan, S. Ringer. Hollow nitrogen-containing core/shell fibrous carbon nanomaterials as support to platinum nanocatalysts and their TEM tomography study, Nanoscale Research Letters, Vol.7, No.165, 2-11, 2012.

[14] K. Chizari, I. Janowska, M. Houllé, I. Florea, O. Ersen, T. Romero, P. Bernhardt, M. J. Ledoux, C. Pham-Huu. Tuning of nitrogen-doped carbon nanotubes as catalyst support for liquid-phase reaction, Applied Catalysis, Vol.380, 72-80, 2010.

[15] K. C. Heo, K. S. Nahm, S. H. Lee, P. Kim. Heat-treated 2,2'-bipyridine iron complex supported on polypyrrole-coated carbon for oxygen reduction reaction, Journal of Industrial and Engineering Chemistry, Vol.17, No.2, 304-309, 2011.

[16] Y. Y. Shao, J. H. Sui, G. P. Yin, Y. Z. Gao. Nitrogen-doped carbon nanostructures and their composites as catalytic materials for proton exchange membrane fuel cell, Applied Catalysis B, Vol.79, No.1-2, 89-99, 2008.

[17] Z. Ao, S. Li. Hydrogenation of Graphene and Hydrogen Diffusion Behavior on Graphene/Graphane Interface. In: Graphene Simulation, Ed. J.R. Gong. Croatia, 53-74, 2011.

[18] M. Terrones, A. Jorio, M. Endo, A. M. Rao, Y. A. Kim, T. Hayashi, H. Terrones, J. C. Charlier, G. Dresselhaus, M. S. Dresselhaus. New direction in nanotube science, Materials Today, Vol.7, No.10, 30-45, 2004.

[19] C. Ewels, M. Glerup, V. Krstić. Nitrogen and boron doping in carbon nanotubes. In: Chemistry of Carbon Nanotubes. Eds. V. A. Basiuk, E. V. Basiuk, American Scientific Publishers, Los Angeles, 4-82, 2008.

[20] S. Dommele. Nitrogen Doped Carbon Nanotubes: synthesis, characterization and catalysis, Ph.D. Thesis, Utrecht University, Utrecht, Nederlands, 2008.

[21] V. O. Khavrus, E. M. M. Ibrahim, A. Leonhardt, S. Hampel, C. Taschner. Simultaneous synthesis and separation of singleand multi-walled CNX nanotubes, CarboCat-III 3 International Symposium on Carbon for Catalysis,Vol.9,
No.12, 17-18, 2008.

[22] J. Teddy. CVD synthesis of carbon nanostructures and their applications as supports in catalysis, Ph.D. Thesis, Toulouse University, Toulouse, 2009.

[23] K. Nikiwe. The synthesis of nitrogen doped carbon spheres and polythiophene/carbon sphere composites, Ph.D. Thesis, University of the Witwatersrand, Johannesburg, 2009

[24] J. C. Mackie, M. B. Colket, P. F. Nelson. Shock-Tube Pyrolysis of Pyridine, The Journal of Physical Chemistry, Vol.94, No.10, 4099-4106, 1990.

[25] A. Kharlamov, G. A. Kharlamova, M. E. Bondarenko. New products of a new method of pyrolysis of pyridine, Russian Journal of Applied Chemistry, Vol.86, No.2, 183-190, 2013.

[26] A. I. Kharlamov, L. N. Ushkalov, N. V. Kirillova, V. V. Fomenko, N. I. Gubareny. Synthesis of onion nanostructures of carbon at pyrolysis of aromatic hydrocarbons, Reports of the National Academy of Sciences of Ukraine, Vol.3, 97-103, 2006. (Russian)

[27] A. I. Kharlamov, S. V. Loythenko, N. V. Kirillova, S.V. Kaverina, V. V. Fomenko. Toroidal nanostructures of carbon. Single-walled $4-, 5$ - and 6 hedrons and nanorings, Reports of the National Academy of Sciences of Ukraine, Vol.1, 95-100, 2004. (Russian)

[28] Z. R. Ismagilov, A. E. Shalagina, O. Y. Podyacheva, A. V. Ischenko, L.S. Kibis, A. I. Boronin, Y. A. Chesalov, D. I. Kochubey, A. I. Romanenko, O. B. Anikeeva, T. I. Buryakov, E. N. Tkachev. Structure and electrical conductivity of nitrogen-doped carbon nanofibers, Carbon, Vol.47, No.8, 1922-1929, 2009.

[29] M. Kim, S. Hwanga, J. S. Yu. Novel ordered nanoporous graphitic C3N4 as a support for Pt-Ru anode catalyst in direct methanol fuel cell, Journal of Materials Chemistry, Vol.17, 1656-1659, 2007.

[30] S. C. Ray, A. Saha, N. R. Jana, R. Sarkar. Fluorescent Carbon Nanoparticles: Synthesis, Characterization, and Bioimaging Application, The Journal of Physical Chemistry, Vol.113, No.43, 18546-18551, 2009.

[31] A. Majumdar, S. C. Das, T. Shripathi, R. Hipple. Chemical synthesis and surface morphology of amorphous hydrogenated carbon nitride film deposited by N2/CH4 dielectric barrier discharge plasma, Composite Interfaces, Vol.1, 1-10, 2012.

[32] A. I. Kharlamov, N.V. Kirillova. New substance: molecular crystals of fullerene-like N-containing molecule of carbon (C50N10)O3H10, Report of Academia of science of Ukraine, Vol.6, 156-163, 2011. (Russian)

[33] O. Kharlamov, G. Kharlamova, N. Kirillova, O. Khyzhun, V. Trachevskii. Synthesis of New Carbon Compounds: N-doped Fullerene (C50N10)O3H10 and "Pyridine" Nanocarbon. In: Technological Innovations in Sensing and Detection of Chemical, Biological, Radiological, Nuclear Threats and Ecological Terrorism. Eds. A. Vaseashta, E. Braman, P. Susmann. Springer, Dordrecht, Netherlands. 245-253, 2012.

[34] A. Hirata, M. Igarashi, T. Kaito. Study on solid lubricant properties of carbon onions produced by heat treatment of diamond clusters or particles, Tribology International, Vol.37, No.11-12, 899-905, 2004. 
[35] D.S. Sua, N. Maksimovaa, J.J. Delgadoa, N. Kellerb, G. Mestlc, M.J. Ledouxb, R. Schlögla. Nanocarbons in selective oxidative dehydrogenation reaction, Catalysis Today, Vol.102-103, 110-114, 2005.
[36] P. J. Benson. Production and analysis of clusters and nanoparticles, Ph.D. Thesis. The University of Georgia, Athens, Georgia, 2007. 